\title{
Digital Transformation and Its Impact on Strategic Supremacy Mediating Role of Digital HRM: an Evidence From Palestine
}

\author{
OHOUD KHATIB \\ Faculty of Economics and Business \\ Palestine Technical University - Kadooriee-PTUK-- Ramallah Branch \\ Ramallah, PALESTINE \\ KHALED ALSHAWABKEH \\ Faculty of Business and Finance- \\ The World Islamic Science \& Education University-W.I.S.E \\ Amman, JORDAN
}

\begin{abstract}
This study aims to identify the impact of digital transformation in achieving strategic sovereignty in a world that is intensely competitive and in a digitalized era. In the study, the human resource management variable serves as an intermediary variable in the relationship between digital transformation and strategic leadership. The study population consists of (420 top and middle) managers in two mobile telecommunications companies in Palestine, namely: Jawwal and Ooredoo. The study is based on the quantitative approach using a proportional stratified sample, as a 201- item questionnaire is developed using the Seven-Point Likert Scale to study the three variables. The independent variable is digital transformation and its dimensions (Business Model, Customer Experience, Digital Processes, and Impact on People), while the dependent variable is Strategic Supremacy including its three dimensions (Scope of Influence, Competitive Configuration, and Competitive Compression), while digital human resources management serves as an intermediate variable. The data contained herein is analyzed by the Smart PLS Program - structural equation modelling (Second Order). The study shows a positive and good impact of digital transformation on strategic supremacy. The same applies to the impact of digital human resources management thereon. The study concludes that even though digital transformation has a very good impact on human resource management, digital human resources management is a mediating variable in the relationship between digital transformation and strategic supremacy, or even a partial mediator.
\end{abstract}

Keywords: Digital Transformation, Digital "HRM", Strategic Supremacy, Business Model, Structural Modeling Analysis (SEM), Customer Experience, Digital Processes, Digital Influence on People, Sphere of Influence

Received: June 22, 2021. Revised: December 28, 2021. Accepted: January 11, 2022. Published: January $14,2022$.

\section{Introduction}

Organizations are racing globally to shift towards the virtual business model, and to maintain a position in the cyberspace of their competitors, in line with the digital hurricane happening to the economic and social organizations. This rabid and vicious race is leading organizations to shift from digitization to digital transformation to digital organization without the need for a traditional physical presence to meet the requirements of digital customers and their needs around the clock.

On the way to achieve superiority and market control with what is known as strategic supremacy; such sovereignty cannot be attained without the human resources department keeping pace with the global transformations in digitization. The Palestinian Telecommunications Sector, in general, and the Mobile Sector, in particular, operates in an intensely competitive environment despite the 
small market size and the insignificant extent of customers compared to other Arab markets. This is in addition to the greater rate of labor on the Palestinian side (skilled and unskilled) working within the Israeli Economy Sectors, which enables them to purchase ther Israeli cellular SIMs. It is worth mentioning that the number of Palestinian labor officially registered in the Israeli market reached 142,000 according to the Palestinian Central Bureau of Statistics 2020. This along with other determinants has contributed to a severe conflict between the two largest cellular communication companies in Palestine (Jawwal and Ooredoo), and resulted in them competing to acquire the greatest market share of sales of their services through a set of additional services accompanying the cellular communication service, which increases the tension of competition. The market of the Palestinian economy is open to the Israeli economy due to the political relationship thereto, in which Israel has a comparative advantage compared to the Palestinian telecommunications sector, and even compared to the world. Israel was ranked among the best countries in the world in terms of the quality and low prices of its telecommunications services, according to (Abu Daqqa, 2018, 8).

\section{Problem Formulation}

2.1 The Research Problem is to answer the main question herein: "What is the impact of digital transformation in achieving strategic sovereignty within the Palestinian cellular communications companies?"

\subsubsection{Research Objectives:}

This research aims to:

- Identify the impact of digital transformation on strategic supremacy in the Palestinian cellular telecommunications companies.

- Identify the impact of digital transformation on the management of digital human resources in the
Palestinian cellular communications companies.

- Identify the impact of digital human resources management on strategic sovereignty in the Palestinian cellular communications companies.

\subsubsection{Research Hypotheses}

H01: Digital Transformation positively impacts Strategic Supremacy.

H02: Digital Transformation positively impacts Digital Human Resources Management.

H03: Digital Human Resources Management positively impacts Strategic Supremacy.

H04: Digital Human Resources Management mediates between Digital Transformation and Strategic Supremacy.

2.3 Literature Review: This part of the research outlines a theoretical background based on the three research variables: Digital Transformation (DT), Strategic Supremacy (SS), and Digital Human Resource Management. (D-HRM).

\subsubsection{Digital Transformation:}

The world of business associated with Internet and social media platforms is imposing shifts in business models that organizations need to adopt to complete their activities and have access to their customers. This digital model may partially affect several organizations around the world, as it is the most common model among business organizations. However, many of these organizations have taken radical means to completely transform to the virtual model. "Digital transformation" as a process aimed at improving an entity, by bringing about significant changes in its characteristics, through combinations of information, computing, communication and technologies" (Vial, 2019). It can also be defined as "The transformation of business activities, processes, products, and models to fully exploit the opportunities of digital 
technologies, which profoundly affects the way value is created and obtained, and leads to the development of new business models, by employing digitalization, to reshape, and innovate the current business model", Bresciani, et. al., (2021, 6). "Modifying processes, products, business models, as well as human behaviors, through digital technologies, aimed at designing businesses' business activities more efficiently and effectively". (Wengler, 2021).

Digital Transformation passes through five successive phases. In other words, it is not possible to reach an advanced phase without passing through the above said five phases. It starts with "Digitization", followed by "Data Integration" leading to "Automation of Operations" moving to "System Integration until the fifth phase, which is the most rational, "Self-Learning System" (Wengler, et. al., 2021). It is the main driver of radical transformations of all types from business organizations to legal institutions, consulting companies in the field of medicine, hospitals, and all service and production sectors. It is the Global Economy (OECD 2020: 5). This is in addition to the hurricane of "Digital Innovation" all-encompassing the world which is "the creation of, and successive changes in, market offerings, business processes, or models resulting from the employment and use of digital technology, driven by a continuous flow effort to increase, expand, and integrate new digital technologies, into broader infrastructure and ecosystems" (Nambisan, et al. ,2017).

Business Model (B.M): Peter Drucker (1985) is considered one of the first to write about Business Model, which he views as the basis of the organization's success and demonstrates how any organization can passes on its products or services to the market, Amma Mehrotra and Velamuri (2021). The time-range perspective presented by DaSilva and Trkman (2013) is intended to clarify the relationship between strategies as a long-term management perspective, which requires dynamic capabilities in the medium term to be able to reach the depicted strategic plan. These capabilities are employed in a business model that demonstrates management practices on the long run. Therefore, the business model is "the way organizations conduct their business." While O'orman (1997) considers that the business model is "the business idea," which distinguishes the internal environment of the organization from its external environment. On the other hand, Teece (2010: 179) considers the business model as "the logic and data that enhances the value proposition to the customer, the structure that can be adopted to generate revenue and the interpretation of cost trends for organizations that adopt the valuecreation pattern that delivers that value".

A business model changes due to several drivers, Rieple and Wikström, (2016), including as the driver of "Disruptive Innovations" which are innovations that create waves of change resulting from developments, especially technical developments, which force strong competitors to change their strategies with skill and strategic agility to seize opportunities or to avoid threats that may afflict their organizations. Thus, leading to the development of new business models. As for the weak organizations, they will face the risk of disintegration or decay. The change in the business model takes several forms which may include changing the mechanisms of conducting businesses or producing innovative services by engaging the customer in designing the service experience or taking part in its performance. The business model changes by disrupting the cultural systems prevailing in the organization and transforming such into customer-oriented systems (Müller and Reichmann 2015, 14). The radical change through which organizations seek to gradually modernize activities and continue the improvement of their operations is a quiet mechanism represented in changing their business models through cumulative improvement and the creation of stable environments and markets (Kodama, 2018,3). Edwards \& Starik, $(2017,48)$ adds. The organization shifts to focus on the "question marks" pattern. In other words, it builds its 
business model on confidence by frequently asking questions about the reasons behind its existence, the changes to its environment, and how to respond appropriately, rather than continue with standard assumptions about its stability and success through ready-made solutions. See Thérin, \& Yoon (2019, xii). Technology complex environments within a fiercely competitive environment "tech entrepreneurship" acts as an active driver for changing the business model of organizations that are operating in an environment characterized by such in which tech entrepreneurship is the activities of start-up companies in a technology-intensive environment.

Mehrotra and Velamuri (2021) believe that secondary innovation is a practical tool for improving and developing business models through successful companies replicating their successful business model while making adaptations to new environments through wellstudied systems for knowledge management and inter-organizational learning, in a diverse learning style through benefiting from the experiences of others and the experiences of consultants, or through partnering with other organizations (such as vendors) in developed countries. That is absorbing knowledge and integrating the information of pioneers; then spreading this learning while adding internalization of each organization and its culture. Likewise, the creative tradition or innovative tradition proposed by Levitt (1966) is one of the engines of developing business models, in which organizations change their business models by purifying, adding value and differentiating in their existing products.

Hence, business model can be viewed as a mechanism selected by organizations to perform their activities in a manner that ensures their persistence and competition within the environmental conditions existing in the economic model in which the organization is operating. It is worth mentioning that digital transformation has become the feature of the era in which we work as a fifth level of human life. The human life started with the hunting era, then moved to the agricultural era, then the industrial era, followed by the technological era, reaching our present era of digital transformation in which organizations thrive to shift to the smart virtual pattern that exceeds every limit to be able to communicate with the greater market through cyberspace. The business model will certainly be characterized by digitization as a mandatory stage, leading to the radical and complete digital transformation of the organization.

The digital transformation in business model means that the organization is to accept all forms of digital products. This may be taking place in its operational pattern for performing its everyday activities, or as innovative digital products, or in the form of converting its traditional products and activities to the digital model. The choice of Ryan Air as a business model of an air carrier with the advantage of low costs resulted in great competitiveness in the face of major airlines. However, its intelligence in employing its economic model by adding optional paid services, such as drinks and meals, enabled it to produce an innovative revenue model. The same applies in terms of shifting payments from the traditional form of metal or paper money to the electronic form between accounts through bank applications on smart mobile phones. This could be considered a gradual and partial shift in the organization's business model. Furthermore, cellular companies were able to digitally transform their business models across cyberspace. Despite the cautions of virtual currencies such as Bit Coin, they continue to rise. The degree of complexity and encryption used thereto is consistent with the cellular communications sector. It will not be long until such crypto currencies find ways to overcome the legal cautions thereof and become one of the most important tools of innovation in business models. A default addition to this is the recent and rapid developments in Circular Economy (CE) Systems and the dependence of industries on renewable energy resources and waste reduction. This requires a technological change to the business models implemented by many 
organizations striving to promote a sustainable economy through business models that are based on "design or engineering for value creation" "delivery, and acquisition mechanisms". (Pieroni and Pigosso, 2020).

Customer Experience (CE): one of the vital pillars in today's world is customer orientation. In other words, institutions build and design their models to meet the needs of customers by identifying such needs and desires, as well as their areas of satisfaction and dissatisfaction through what is known as "Customer Experience" which is a knowledge management process to get to know the customer. According to Grzybowska (2016), $\mathrm{CE}$ is "a process of interactions between an organization and a customer over the duration of their relationship". These interactions may include the customer's attraction, awareness, discovery, cultivation, advocacy, purchase of goods, and use of services. Moreover, Lemon and Verhoef (2016) define CE as a customer journey with the firm over time from pretransaction (including search) to transaction to post-transaction.

Modern digital technologies can be employed to enhance levels of trust and interaction between the company and the customer, such as RFID chip technology, which logically employs Internet of Things (IoT) Technology to employ product information, locate and manufacture materials, distribute points, and how it can be delivered home. This is in addition to the use of "Smart Mirrors" Technology to test products in the spare rooms acting as a smart advisor to the consumer when trying the item in the changing room. Smart Mirrors indicate how well the product fit with your body and the occasions where you can wear such in the future. They also indicate how to mix or coordinate clothes. Moreover, this feature can be enhanced with the technologies of augmented reality / virtual reality / mixed reality (AR / VR / MR) into a futuristic mirror of the reality by trying clothes in different lighting conditions or different contexts (in the office or in the street) and occasions (parties or business meetings) providing a list of people who have bought the item. Things can go even further to predict he customer's satisfaction with the product based on previously analyzed personality and a bot may come across the customer and helps with what are known as chat bots (Hoyer, et al., 2020).

\section{Digital Process (D.P): Organizations'} traditional operational processes are based on a mixture of employment and automation. However, the introduction of technology contributed to transformations that started gradually and then became radical. The evolution of the operating stages in the manufacturing process can be viewed according to (Margherita, and Bua, 2021)

Table1. The Development of Manufacturing Operators Stages

\begin{tabular}{|c|c|c|}
\hline Operator & $\begin{array}{c}\text { Manufacturing } \\
\text { Style }\end{array}$ & Execution \\
\hline 1.0 & $\begin{array}{c}\text { Traditional } \\
\text { Manufacturing }\end{array}$ & $\begin{array}{l}\text { Hand and dexterous } \\
\text { work with some } \\
\text { support from } \\
\text { mechanical tools } \\
\text { and manually } \\
\text { operated machine } \\
\text { tools }\end{array}$ \\
\hline 2.0 & $\begin{array}{c}\text { Assistant } \\
\text { powered by PC } \\
\text { Tools }\end{array}$ & $\begin{array}{c}\text { Computerized } \\
\text { numerical control } \\
\text { machines - and } \\
\text { information's. } \\
\text { systems. }\end{array}$ \\
\hline 3.0 & $\begin{array}{l}\text { Operating with } \\
\text { computer tools } \\
\text { robots, other } \\
\text { machine parts. }\end{array}$ & $\begin{array}{l}\text { Manual activities, } \\
\text { such as collecting, } \\
\text { or handling } \\
\text { products carried out } \\
\text { by these new } \\
\text { technologies. }\end{array}$ \\
\hline
\end{tabular}




\begin{tabular}{|c|c|c|}
\hline $\begin{array}{c}4.0 \\
\text { (OP40) }\end{array}$ & $\begin{array}{l}\text { works in an } \\
\text { Industry } 4.0 \\
\text { assembly line }\end{array}$ & $\begin{array}{c}\text { cognitive and } \\
\text { physical } \\
\text { interactions, } \\
\text { wearable trackers } \\
\text { enable both } \\
\text { interactions, } \\
\text { technologies allow } \\
\text { for the tracking and } \\
\text { monitoring of } \\
\text { operator activities, } \\
\text { heart rate, health- } \\
\text { related metrics }\end{array}$ \\
\hline
\end{tabular}

In the cellular communications sector, the industry is focused on providing services of cellular frequency, sale of SIM cards, smart devices, and the accessories thereof. However, digital transformation forced these companies to adopt new types of goods and products known as digital products, which "are goods that can be delivered over a digital network. Music tracks, video, Hollywood movies, software, newspapers, magazines, and books can all be expressed, stored, delivered, and sold as purely digital products. Currently, most of these products are sold as physical goods". (Laudon and Laudon,2016,380). Moreover, Loebbecke (2003) defines such as "goods that can be fully expressed in bits so that the complete commercial business cycle can be executed based on an electronic infrastructure such as the Internet". The revolutionary impact of Internet on the market can be described as a "digital hurricane" in several areas, including:

Table2. Characteristics of Digital Products

\begin{tabular}{|c|c|c|}
\hline $\begin{array}{c}\text { Production of } \\
\text { the initial } \\
\text { unit of the } \\
\text { digital } \\
\text { product } \\
\end{array}$ & very high & \multirow{2}{*}{$\begin{array}{c}\text { (Laudon and } \\
\text { Laudon, 2016, } \\
\text { 380). }\end{array}$} \\
\hline $\begin{array}{c}\text { Marginal cost } \\
\text { of adding a } \\
\text { new unit }\end{array}$ & $\begin{array}{l}\text { Almost zero } \\
\text { (file copies) }\end{array}$ & \\
\hline Storage costs & low & \multirow[b]{2}{*}{ Researchers } \\
\hline $\begin{array}{l}\text { Marketing } \\
\text { costs }\end{array}$ & $\begin{array}{l}\text { Unchanged } \\
\text { (based on } \\
\text { digital and }\end{array}$ & \\
\hline
\end{tabular}

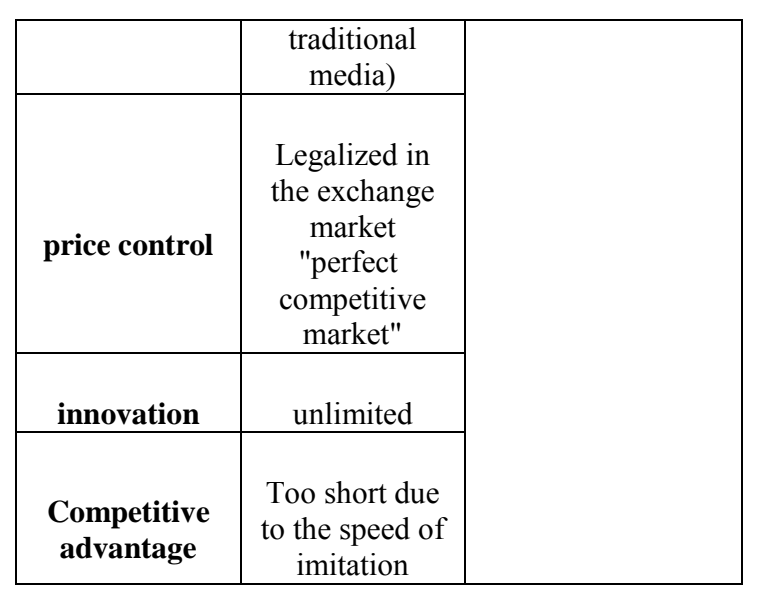

Digital Influences of People (PoI): Digitization has significantly affected the behavior of individuals, Adhiarso, et. al.,(2018). He added "that digital communication tools or Java communities are gradually shifting to the individual style, moving away from the direct social exchange, so that human society in general turns to the individual style”.

OECD $(2019,2)$ Report indicates that " despite the focus on mastering digital skills, it is necessary to focus on a range of emotional and social skills in order to take full advantage of digital technologies for fear of excessive health risks, while it is believed that not everything online is good despite all advantages of the Internet given the risks related thereto such as destructive behavior or the use of algorithms that shake the foundations of democracy".

It can be said that the digital impact on people's lives ranges from facilitating advantages to life, in general, at the personal, professional, and societal levels, and introducing some cautions that must be seriously considered especially at the level of organizations with influential and important social interaction, such as universities and schools. For instance, digital addiction and the noticeable increase in household finances due to the use of smart devices and digital products are critical cautions. Therefore, parallel strategies for digital transformation processes must be drawn up. These can be referred to as "digital shadow strategies" aimed at analyzing the risks of digital transformation on humans, to ensure consistency with transformation 
processes. As a compass to correct deviations and reduce risks to the social integration of the humans.

\subsubsection{Strategic Supremacy (SS):}

Strategic Supremacy is not a modern term or human invention. It is the basis of human conflict ever since the beginning of time. The best description of supremacy in this context is "dominance". Dominance herein is more powerful in expression compared to other possible terms related thereto such as power, influence, or the exclusion of competitors. Even though these terms are all requirements for dominance. In brief, it is the ability to change the rules of the game and control decision-making. This is supported by Habermas who referred to this back in in 1981 as the colonization of the world or the colonization of the living world. This is already the key engine to social, economic, and technological domination. Consequently, this gave corporations the ultimate domination over mankind social life due to acquiring legal and economic privileges. (Jones, 2015, 17).

Strategic supremacy can be described as administrative capabilities resulting from the efforts of managers observance or environment foresight. Although this is true, but not categorically. As strategic supremacy is a cultural pattern supported by the organization's management, and spreads at all levels, according to Kotze (2003, 109), who also pointed out that it is "creating and maintaining a culture of strategic thinking" and spreading such among the largest possible number of administrative levels. It is the task of the strategic leader to have access to an employee, supervisor, and manager, who is working and thinking about strategic issues. It contributes to creating strategic value, through its nearly constant day-to-day operations given "this is the way things are done".

Strategic supremacy could also be defined as "building new advantages to replace the old in order to move competitors and push them to continue competition and expand their influence by providing value to the recipient of the service or commodity in directions that do not conflict with their ambitions so that they can shift their resources against other competitors" (D'Avenie, 2004: 37). As for AlKinani, and Al-Najjar (2021), they define it as "the organization's strength and dominance over large competitive areas, and its ability to influence those areas subject to the influence of other competitors in the market". Furthermore, Hasan and Al-Sheikli (2020) refer to strategic supremacy as "a technique that reveals whatever the organization does and its reason for seeking its goals that it desired to achieve in future". Strategic supremacy management is the special management style that does not eliminate a basic management principle such as planning, organization, execution, and control. As it is concerned with the higher level. It is a process of planning, organizing, coordinating, and controlling the work to be done so as to take the organization to its preferred position.

Moreover, strategic supremacy management can be described as a roadmap for the future. In this context, many management techniques are used to analyze the organization's supremacy situation via strategic techniques such as the Nominal Group Technique, SWOT Analysis, Portfolio Analysis, Vision and Mission, Benchmarking, (Mohammed and Mohammed, 2021). The most important tool of strategic supremacy "planning for strategic supremacy" which shows which ways will be used in the future to reach the desired goals and determines the ways to be followed under a framework of strategies which represents the basic values of strategic supremacy management. (Rashid and Muttar, 2020). Strategic supremacy generates power strategies in organizations focused on market dominance based on three principles: (Zee \& Strikwerda, 2003: 15) (Al-Bashqali \& Sultan, 2021) namely, (a) Perception which is a special force of competitors. It reflects the organization's ability to shape and synthesize a social reality in which competitors in the industrial sector join the competitive field, (b) the power of appropriation focused on attracting the loyalty of the "mind and emotion" of customers over the hearts and minds of primary customers. It 
is a customer-oriented force, where companies focus on quality and competitive price, (c) Business Environment-oriented force aimed at designing a business environment ranging from attack and defense, to competition, and sometimes cooperation and alliances to strengthen strategic supremacy.

To own up the game rules, organizations must have three dimensions. (1) Sphere of Influence" (SoI) which defines the social and market domain that can play a part within as a strategic force. According to Hasan, and AlSheikli (2020), organizations operating in highly competitive environments usually reallocate resources to reshape their competitive space given the intensity of the competition. This basically conveys the organization's products portfolio in areas that have strong points and market control (AlKinani, and Al-Najjar ,2021). It denotes the field of influence and the force relationship (Hast $(2016,5)$. (2) Competitive configuration focused on the construction and competitive formation. It is the result of deliberate and focused processes of competitive training by directing the organization's strategy towards alliances and partnerships. In this context, it is necessary for the organization to ascertain and ensure its internal capabilities so that such partnerships may turn into competitive advantage and not merely partnerships compared to other competitors. Thus, Competitive Configuration (C.CON) is a process implemented by organizations that seek and strive to supremacy periodically to analyze the structure of industry in an attempt to break through the state of competitive balance and reach superiority given the difference in companies or organizations behavior, or due to discrepancy and frequent fluctuations in the industry structure itself, calling for follow-up analysis of the industry structure. (Al-Kinani, and Al-Najjar, 2021). (3) "Competitive Pressure" (C.COM) that represents the ability of organizations to survive competitive pressures imposed by other competitors. From a marketing perspective it may be argued that in addition to the three abovementioned dimensions, the oscillatory strategies are also employed by organizations that strive for sovereignty, and it may range between fierce competition in cases where they are able to hit the competitor. It is a sovereign strategy as the competitive field is not always favorable. Therefore, companies striving for sovereignty have to adjust rapidly with alliances and cooperate with competitors to form focal structures to assume the process of market control based on less dominant competitors. The desire to dominate the market by strong companies allied with competitors can be referred to as "Cooperative Competitive Fluctuation". Given the importance of focusing on customer loyalty throughout all stages and activities of the organization through Customer Attraction, organizations may be preoccupied with their sovereign battles and disregard the changes in customer needs resulting in a gap that is created due to the ability of the customer to access the large market via the Internet. Companies seeking sovereignty must not lose guidance to the customer through the use of electronic platforms and the allocation of budgets and resources to analyze data and learn about the changes in customer needs. It is necessary to establish in the attitudes of organizations and marketing strategists an important market rule that "there is no absolute loyalty of customer, as the customer's loyalty is always intended for the added value to maximize their benefits". - (See Figure1).

Today, digital transformation has entered all fields of life to enable strategic excellence and supremacy tools so companies can create value to reach sovereignty through the seamless integration of digital and physical processes so as to improve operations and assets, or through closeness with customers, or through operational excellence. Excellence is also used in information and advanced algorithms to lead solutions of connecting smart products and services with social media to produce integrated solutions and systems for product service systems. Weinman $(2015,6)$ contributed to identifying four digital disciplines acting as drivers and catalysts for strategic supremacy, namely: information excellence, solution leadership, collective 
intimacy, and accelerated innovation. These are considered as technological tools that stimulate sovereign strategies. As information excellence contributes to the ability of exploiting technological potential of information and allocating advanced algorithms in a manner that serves the company's strategic dominance and superiority by improving operational processes. This is similar to what Uber has done by synthesizing digitization with its field and material nature to reach what is known as "operational excellence" compared to competitors. That is, creating a unique value for customers.

"Solution leadership" is a process of deep thinking and a procedure to develop smart products and services by converting such from one-time exchange transactions to build a longterm relationship with customers through linking sales operations with cloud applications so that consumers' data and desires can be a flexible tool to develop valuable solutions therefor. It also contributes to sales preferences for the company compared to traditional competitors to turn into a strategic dominant market.

The other driver referred to as "Accelerated innovation' is the lever for the organization's operations. It invests in innovation and improvement of cash-generating products as a pillar of Strategic Supremacy, by providing the company with product packages that are faster, less expensive, and more valuable to the customer. An example thereof is Apple that invests in innovation to generate fastdischarge, and high-return products. Collective intimacy is the behavioral pillar of strategic supremacy to convert sales transactions from mere anonymous relationships to long-term interactive relationships by investing in "big data" analysis to simulate the characteristics and behavior of customers and build profitable relationships so that sales shift from potential demand to predictive and commensurate with the customer's personality and preferences, such as Amazon.com

This significance of strategic supremacy can be illustrated through an environmental analysis which shall enable organizations to reduce or even change the behavior of competitors to serve their interests thereof and increase the probability of competing faster and more confidently. Al-Kinani, and Al-Najjar (2021).

However, the crucial question remained: Is investing in "exploratory and exploitative" innovation and ingenuity still a strategic option? The answer is that it may be an option for companies that take risks for its survival as in the case of organizations aware of how fierce the competition is in an open digital world with highly Tech-savvy and all means of empowerment, the most important of which is the "Internet of Things". It is a pattern that may be described as a cancer that feeds on everything it reached to expand, grow, and increase. This enormous power was realized by many companies such as "Netflix", which became able to realize its efforts in marketing by understanding its working mechanism. Weinman, Joe (2015) explains how the "" works by creating "exponential value" for a huge set of real data. This is taking place in reality linked to smart devices such as updating the status on social media to turn into predictive algorithms. On the other hand, Yaïci, et al. (2021) describes the architectural perspective of the "Internet of Things" as "the interconnection between smart devices and sensors through controllers linked to cloud applications to transfer data in real time for controllers and provide immediate responses, so as to enable algorithms to perform adaptive and predictive operations".

\subsubsection{Digital Human Resource Management} Digital transformation along with the increasing number of millions of people using the Internet and engaging in the digital world have imposed changes to the nature of work and workers involved in technology-integrated organizations, given the rapid developments to follow up in the digital environment. Donnelly \& Johns (2021) explain "Digital employee management" as "the planning, implementation, and in particular application of digital technologies to support and network the HR profession, a phenomenon also known 
as electronic HRM'. (Bondarouk and Ruël, 2009).

The digital field of human resources management will give more flexibility in working times and greater diversity in harmony. That is work will be more efficient and smarter. (Strauss, 2018). However, it will provide an environment for challenges. These challenges include legal disputes about the nature of contracts. This is in addition to the diversity in the amount of work and the place of performance as well as the difference in timing. (Donnelly and Johns, 2021). Furthermore, the despite the advantages of flexibility of working hours, it may lead to demands for achievement without taking into account the privacy of individuals and their public life (Cooper \& Lu, 2019). Another challenge, is the social inequality in the access to digital spaces which may be noted among some workers due to considerations of countries and divisions between classes and urban sites (Neufeind et al., 2018).

The changes in human force towards digitization are led by four drivers: (a) the administrative engine and the apparent increase in complexity processes, (b) temporary parttime contracts or the periodical system increase, (c) contractual drivers where the nature of modern work is individualistic and (d) contracting with experts individually, and spatially towards smaller work units of a solitary nature.

Studies indicate that digital human resource management specifies fundamental shifts in human resource management functions in terms of the mechanism of practice and not in terms of professional content recruitments, training, compensation and other human resource functions. However, the mechanism of its implementation changes with the change of technology. If the evolution in the concept of employees in the Human Resources Department is tracked, one can note that "digital employees" was an expression of a changing role from the automated office work pattern to the electronic one. Then there is the "Millennial Generation" or the "Net
Generation". Parry and Strohmeier. (2014). However, the concept has turned into the same function to indicate that there are differences between older employees and younger employees in terms of experiencing less complex work patterns compared to digital work patterns that the younger employees are more familiar with (D'Netto and Ahmed, 2012).

The problem of human resources in the digital era may appear more clearly in industrial organizations that adopt (4.0) technology such as robots and the "Internet of Things" as a central weight in manufacturing processes, Elia, et al., (2021). Human resources management process turned to a fundamentally transformative nature, especially in terms of training and crew synthesis processes with computer thinking.

Despite the enormous capabilities of digital transformation and the breakthrough innovations in entrepreneurship that resulted thereof, it is necessary to validate the social impact on human resources in particular.

\section{Problem Solution}

\subsection{Sample and Data Collection}

To test the hypothesis mentioned above, a survey is conducted targeting cellular communication companies in Palestine (Jawwal Company, Ooredoo Company) starting $18^{\text {th }}$ to $28^{\text {th }}$ September 2021. The researcher targeted a sample of middle and upper managers in both companies as they represent the decision-making category, and their role is to participate in drawing up strategies, which is the focus of the research. The number of the study population amounted to 420 mangers (252 from Jawwal Company, while 168 from Ooredoo Company) under the categories (Head of Department, Assistant Director, Director). The survey was conducted based on stratified sampling. The sample size used in the analysis is 201 mangers (122 from 
Jawwal Company, while 79 from Ooredoo Company). Cross-sectional data is collected through online distributed of the survey via email to all mangers. Table (3) below elaborates the sample characteristic.

Table 3. Sample characteristics

\begin{tabular}{|c|c|c|c|}
\hline & & Count & $\begin{array}{c}\text { Percentage } \\
(\%)\end{array}$ \\
\hline \multirow[t]{2}{*}{ Gender } & Male & 119 & 59.20 \\
\hline & Female & 82 & 40.80 \\
\hline \multirow[t]{4}{*}{$\begin{array}{c}\text { Job } \\
\text { description }\end{array}$} & $\begin{array}{c}\text { Head of } \\
\text { Department }\end{array}$ & 95 & 47.26 \\
\hline & $\begin{array}{l}\text { Assistant } \\
\text { Director }\end{array}$ & 50 & 24.88 \\
\hline & Director & 56 & 27.86 \\
\hline & Undergraduate & 138 & 68.66 \\
\hline \multirow{2}{*}{$\begin{array}{c}\text { Educational } \\
\text { Level }\end{array}$} & Postgraduate & 63 & 31.34 \\
\hline & Less than 5 & 61 & 30.35 \\
\hline \multirow{3}{*}{$\begin{array}{c}\text { Years of } \\
\text { Experience }\end{array}$} & 5 - less than 10 & 73 & 36.32 \\
\hline & 10 - less than 15 & 39 & 19.40 \\
\hline & 5 and More & 28 & 13.93 \\
\hline
\end{tabular}

\subsection{Measurements}

The study adopted a seven-point Likert scale as it can provide many options to increase the probability of discovering the objective reality of the respondents, and the "raw" description of the idea behind the subject of the research.

Table4. Seven-Point Likert Scale

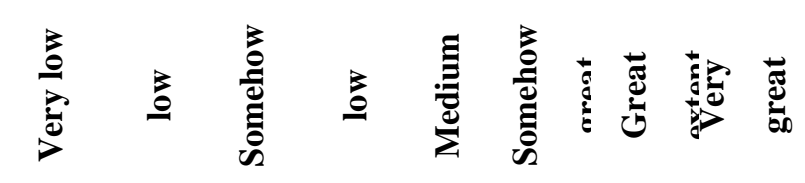

$$
\begin{aligned}
& \begin{array}{lllllll}
1 & 2 & 3 & 4 & 5 & 6 & 7
\end{array}
\end{aligned}
$$

The study consisted of three variables: (1) The independent variable "Digital Transformation" measured through four sub-dimensions "Business Model, Customer Experience, Digital Process, and Impact on People", (2) The dependent variable "Strategic Supremacy measured by the sub-dimensions "Sphere of Influence, Competitive Configuration, and competitive Compression". (3) "Digital Human Resource Management" introduced as an intermediate variable. These variables were used to examine and evaluate the impact of digital transformation on strategic supremacy. See Figure 2.

\subsection{Data Analysis}

To test the research hypotheses, the Structural Equation Modeling (SEM) is used. It is a second-generation type of modeling that examines the predictive ability of the model explaining the variance of endogenous variables (Richter et al.2016). There are two types of SEM: (1) the covariance-based SEM (CBSEM), and (2) the variance based (PLSSEM). The variance-based partial least square structural equation modelling (PLS-SEM) is used in this study since PLS-SEM can estimate a study model with a large number of underlying variables and indicators (Chin et al., 2008). It further works effectively on small-sample size (Hair et al., 2017), and it does not require any distributional assumptions (Henseler et al., 2014). Smart PLS version 3 (Ringle et al., 2012) software package is employed herein.

3.4. Result: to evaluate the research model, two steps of analytical procedure are followed: (1) measurement evaluation (validity and reliability of the measures), and (2) structural model evaluation (research hypothesis evaluation).

\subsection{Measurement Model Evaluation}

There are three main stages to evaluate the measurement model: (a) the assessment of internal consistency, (b) the convergent 
validity, and (c) discriminate validity. The result of internal consistency, convergent validity and discriminate validity are shown in Table 2 for the first-order and the second-order construct as Sarstedt et al(2019) recommended

\subsubsection{Internal Consistency Reliability}

The internal consistency is assessed by the Cronbach's $\alpha$ coefficient (CA) and the Composite Reliability (CR). According to the result shown in Table 2, the CA value for the first-order and second-order construct are found to range between $0.679-0.884$. This which indicates an excellent internal consistency among the constructs (Hair et al., 2010). Composite reliability values above 0.70 are considered satisfactory (Hair et al., 2017). The models CR values of constructs are 0.819 and above for all constructs which is satisfactorily and meets the cutoff value.

\subsubsection{Convergent Validity}

Both outer loading and Average Variance Extracted (AVE) are used or the assessment of convergent validity of the measurement model. Hair et al. (2010) suggested that if the indicators with outer loading are more than 0.50 , they can be accepted in the model. Furthermore, Fornell et al. (1981) suggested that the AVE should be greater than 0.50 . Accordingly, that the outer loading of all indicators that is between 0.591 and 0.867 tindicates that all indicators are acceptable, while the result of AVE values of all constructs are suggesting convergent validity is ensured (see Table 5,6).

\subsubsection{Discriminate Validity}

Table 3 and Table 4 report the result of discriminate validity of constructs examined by Fornell-Larcker criterion of first-order and second-order. The Fornell-Larcker criterion is more conservative to examine the discriminate validity. It compares the square root of AVE values of each construct (in bold in the matrix diagonal) with the paired construct correlation (off-diagonal). It can be noticed that all values of square root of AVE are greater than the constructs correlation. Hence, the discriminate validity is satisfactory (Fornell et al., 1981). The higher correlation found between every pair of constructs is between Digital Human Resource Management and Digital Transformation (0.684), followed by the correlation between Customer Experience and Digital Process (0.646).-see table 7-

Table 8. Fornell-Larcker Criterion for SecondOrder Construct

\begin{tabular}{cccc}
\hline & D.HR.M & DT & SS \\
\hline D.HR.M & $\mathbf{0 . 7 6 2}$ & & \\
DT & 0.684 & $\mathbf{0 . 8 2 4}$ & \\
SS & 0.494 & 0.500 & $\mathbf{0 . 7 7 6}$ \\
\hline
\end{tabular}

Note: Diagonals in bold represent the square root of each construct AVE. Off-diagonal represent the constraint's correlation

\subsubsection{Structural Model Evaluation}

After the reliability and validity of the constructs are established, the second step is to examine the structural model which estimates hypothesized paths between the constructs. To assess the structural model Co linearity Test, Path Significance, Coefficient of Determination, and the Predictive Accuracy are used.

3.5.6. Co linearity Test: this is the first step to assess the structural model according to the 
result shown in Table (5) were no presence of Collinearity in the structural model is seen since all Variance Inflation Factors of all construct are below 5 (Hair et al., 2017).

Table 9. Co linearity Assessment

\begin{tabular}{|c|c|c|c|}
\hline & D.HR.M & DT & $\mathrm{SS}$ \\
\hline SOI & & & 1.000 \\
\hline C.Com & & & 1.000 \\
\hline C. Con & & & 1.000 \\
\hline $\mathrm{BM}$ & & 1.000 & \\
\hline $\mathrm{CE}$ & & 1.000 & \\
\hline D.HR.M & & 1.000 & \\
\hline DP & & 1.000 & \\
\hline IOP & & 1.000 & \\
\hline SS & 1.877 & 1.877 & \\
\hline
\end{tabular}

\subsubsection{Path Coefficient}

Table 6 shows the path coefficient of all hypotheses and their t-values associated with p-values. Research model proposed a total of four hypotheses. The first three thereof propose a direct relationship, while the last one propose an indirect relationship. According to the result, all hypotheses are supported. In other words, there is a significant and positive relation between digital transformation and strategic supremacy $(\beta=0.304, t=3.512)$ and this supports $H_{1}$.Moreover, there is a significant and positive relationship between digital transformation and digital human resources management $(\beta=0.684, t=$ 18.895) supporting $\mathrm{H}_{2}$. Additionally, there is a significant and positive relation between digital human resources management and strategic supremacy $\quad(\beta=0.286, t=4.198)$ supporting $\mathrm{H}_{3}$. Furthermore, digital human resources management significantly mediate between digital transformation and digital human resources management $(\beta=0.684$, $t=18.895)$ supporting $H_{2}$. There is also a significant and positive relation between digital human resources management and strategic supremacy $\quad(\beta=0.286, t=4.198)$ supporting $H_{3}$. Digital human resources management significantly mediate between digital transformation and strategic supremacy ( $\beta=0.196, t=4.080)$ supporting $H_{4}$. This confirm that digital human resources management acts as a partial mediator occasionally between digital transformation and strategic supremacy. (See Table 9)

\subsubsection{Coefficient of Determination $\left(R^{2}\right)$ and Predictive Relevance $\left(Q^{2}\right)$}

A major part of the structural model evaluation is the assessment of coefficient of determination $\left(R^{2}\right)$ and predictive relevance $\left(Q^{2}\right)$. The Coefficient of Determination $\left(\boldsymbol{R}^{2}\right)$ represents the amount of variance in the endogenous construct that is clarified by all of the exogenous constructs. Hair et al. (2017) suggests that if $R^{2}$ value is 0.25 it means its weak, while if 0.50 and 0.75 then it is 
moderate and strong respectively. Furthermore, Falk and Miller (1992) recommend that the minimum required value of $R^{2}$ should be at least 0.10 . To assess the Predictive Relevance $\left(\boldsymbol{Q}^{2}\right)$ value a blindfolding procedure relevance, Chin (1998) and Henseler et al.(2009) suggest that a model confirm a good predictive relevance when its value is greater than zero.

According to the result in the Table of $R^{2}$ and $Q^{2}, 46.7 \%$ of variations in digital human resources management can be explained by construct of digital transformation, while $29.3 \%$ of variations in strategic supremacy can be explained by construct of digital human resources management and digital transformation (See Table 10.11).

\subsubsection{Effect Size $\boldsymbol{f}^{2}$}

The Effect Size $f^{2}$ is used to estimate the effect of specific exogenous constructs that contribute to an endogenous construct by means of change if deleted from structural model. Chin (1988) and Cohen (1988) suggest that the $f^{2}$ value of $0.02,0.15$, and 0.35 are often used to represent small, medium, and great effect, respectively. According to the result shown in Table 8 , the exogenous variables digital human resources management and digital transformation have a medium effect on strategic supremacy, where digital transformation has a great effect on digital human resources management.

Table 12. Effect Size of Exogenous constructs

\begin{tabular}{lccc}
\hline & $\begin{array}{c}\text { Exogenous } \\
\text { constructs }\end{array}$ & & \\
\hline Endogenous & D.HR.M & DT & $\begin{array}{c}\text { Effect } \\
\text { size }\end{array}$ \\
constructs & & 0.877 & $\begin{array}{c}\text { Great } \\
\text { effect }\end{array}$ \\
D.HR.M & & 0.070 & $\begin{array}{c}\text { Medium } \\
\text { effect }\end{array}$ \\
\hline
\end{tabular}

\section{CONCLUSION}

The study concludes that there is a positive and good impact of digital transformation on strategic supremacy. The same applies to the impact of digital human resource management on strategic supremacy, while digital transformation has a very good impact on human resource management. Relevant studies show that digital transformation is effective in cases of transformation of industrial organizations from the traditional pattern to the industry 4.0 pattern. Digital transformation imposes a transformational reality in human resources management to maintain a strategic function. It further concludes the importance of the role that human resources management must play in the digital age to spread the culture of Digital transformation within organizations and build human resources capabilities that fit into the digital era. 
The results of the study also show that Digital Human Resource Management serves as mediating variable in the relationship between digital transformation and strategic supremacy, and as a partial mediator, not as strong as expected. It is also noted that the direct impact of digital transformation on strategic supremacy is higher than the indirect impact.

This study also addresses the expected effect of digital transformation in competing and market fencing industries, especially in sectors where markets are characterized by oligopoly, such as Mobile Communications in Palestine, in which only two companies compete towards Strategic Supremacy. On the other hand, the study introduces the role of Digital Human element as a mediating variable to clarify the crucial role that the trained human resources play in digital transformation processes in the existing digital era.

The study provides insights of digital transformation from an internal perspective of "digitizing business models and digitized operational processes". This is in addition to an external perspective of customers' expectations and their experience in digitized companies as well as the expected impact of digitization on humans. The understanding of corporate management of the mechanism of their digital transformations will contribute to a clear understanding of the new rules of the game in strategic supremacy and their response to market pressures.

\section{Practical Implications}

The results of this study are useful for policy makers in companies concerned with digital transformation. Seeking to extend their market dominance over competitors, drawing the lines of competition in the digital world depends on the organization's ability to transform from digitized organizations to smart organizations (Wengler, et al.,2021).

\section{Recommended Studies}

Researchers recommend that more in-depth studies be conducted to examine the impact of digital transformation on strategic sovereignty using more variables such as digital empowerment and financial allocations.

The study also recommends further studies be developed on digital competencies in digitally transformed organizations into smart organizations

\section{References}

[1] Adhiarso ,Dendy Suseno , Utari Prahastiwi\& Hastjarjo Sri (2018). The Impact of Digital Technology to Change People's Behavior in Using the Media. Digital Press Social Sciences and Humanities 2, Conference: Proceeding of The American Studies International Conference (ASIC) 2018, : 35-40 https://doi. 10.29037/digitalpress.42256UGM 2:

[2] Al-Bashqali, Mahmoud Muhammad Amin, \& Sultan, Hikmat Rashid(2021). The role of 
strategic improvisation in achieving strategic sovereignty: An exploratory study of the opinions of administrative leaders in a sample of private universities in the Kurdistan Region of Iraq. The Arab Journal of Management, 41( 1),95-126.

[3] Al-Helli, S. M. H. A., Al-Hindawy, Z. A. U. A., \& Jaber, A. S. (2021). Effect the organizational virtuousness on strategic supremacy: An analytical research study at Etihad Food Industries Company Ltd. Journal of Statistics and Management Systems, 1-7.

[4] Al-Kinani, Haider and Al-Najjar Shahnaz (2021). The role of disclosure in achieving strategic supremacy for business organizations. Al-Kut University College Journal for the Humanities. 2(1),53-68

[5] Ankur, Joshi \& Dinesh Kumar Pal(2015). Likert Scale: Explored and Explained. Current Journal of Applied Science and Technology 7(4):396-403 DOI: https:// 10.9734/BJAST/2015/14975

[6] Benedict .wauters(2017). Strategic management in the public sector: atool for improving performance of ongoing operations or for redefining performance to meet new challenges? A challenge paper for discution.Report to the European commission's public administration and Governance network, March2017

[7] Bissola, R., Imperatori, B., HRM 4.0: THE DIGITAL TRANSFORMATION OF THE HR DEPARTMENT, in Cantoni, F., Mangia, G. (ed.), Human Resource Management and Digitalization. The Effects of Industry 4.0 on Human Resource, Routledge, Abingdon-onThames 2018: 51- 69 [http://hdl.handle.net/10807/121548]Bondarou k, T.V. and Ruël, H.J.M. (2009), "Electronic human resource management: challenges in the digital era", International Journal of Human Resource Management,. 20 (3),505-514

[8] Bresciani, S., Ferraris, A., Romano, M. and Santoro, G. (2021), "Building a Digital Transformation Strategy", Digital Transformation Management for Agile Organizations: A Compass to Sail the Digital World": Emerald Publishing Limited, Bingley. https://doi.org/10.1108/978-1-80043-171$\underline{320211002}$

[9] Bresciani, S., Ferraris, A., Romano, M. and Santoro, G. (2021), "Building a Digital Transformation Strategy", Digital Transformation Management for Agile Organizations: A Compass to Sail the Digital World": Emerald Publishing Limited, Bingley. https://doi.org/10.1108/978-1-80043-171320211002

[10] Chin, W. W. (1998). Commentary: Issues and opinion on structural equation modeling.

[11] Chin, W.W., Peterson, R.A., Brown, S.P., 2008. Structural Equation Modeling in Marketing: Some 618 Practical Reminders. J. Mark. Theory Pract. 16, 287-298. doi:10.2753/MTP1069-6679160402

[12] Cohen, J. (1988). Statistical power analysis for the behavioral sciences (No. 300.72 C6).

[13] Cooper, C., $\quad \&$ Lu, L. (2019). Excessive availability for work: Good or bad? Charting underlying motivations and searching for game changers. Human Resource Management Review, 29(4), 100682.

https://doi.10.1016/j.hrmr.2019.01.003

[14] D,Aveni Richard A.,( 2004), "Corporate spheres of Influence" , mission management Review ,Vol.45,No.4 , P: 34-46

[15] DaSilva,Carlos Marques \& Trkman Peter (2013).Business Model: What it is and What it is Not Business Model: What it is and What it is Not. Long Range Planning, (1), https://doi: 10.2139/ssrn.2181113

[16] D'Netto, B. and Ahmed, E. (2012), "Generation Y: human resource management implications", Journal of Business and Policy Research, 1-11

[17] Donnelly, R., \& Johns, J. (2021). Recontextualising remote working and its HRM in the digital economy: An integrated framework for theory and practice. The International Journal of Human Resource Management, 32(1), 84-105.

[18] Edwards, M., Benn, S., \& Starik, M. (2017). "Business cases for sustainabilityintegrated management education". In Handbook of Sustainability in Management Education. Cheltenham, UK: Edward Elgar 
Publishing.

doi:

https://doi.org/10.4337/9781785361241.00010

[19] Elia, Gianluca, Alessandro Margherita,

Enrico Ciavolino, and Karim Moustaghfir.

2021. Digital Society Incubator: Combining

Exponential Technology and Human Potential to Build Resilient Entrepreneurial Ecosystems. Administrative Sciences MDPI Journal 11: 96. https://doi.org/10.3390/ admsci11030096

[20] FAbu Daqqa, Mashhour (2018). The Competitiveness of Telecommunication Prices in Fatin: The Palestinian Economic Policy Research Institute (MAS). April 2018

[21] Falk, R. F., \& Miller, N. B. (1992). A primer for soft modeling. University of Akron Press.

[22] Fornell, C., \& Larcker, D. F. (1981). Evaluating structural equation models with unobservable variables and measurement error. Journal of marketing research, 18(1), 39-50.

[23] Gómez Jaime , Orcos Raquel \& Palomas,Sergio(2018). Operating under the radar in spheres of influence: Taking advantage of industry leaders' market domains. Sage journal, 18(2) 275-300. s https://doi.org/10.1177/1476127018804186

[24] Hair Jr, J. F., Hult, G. T. M., Ringle, C., \& Sarstedt, M. (2017). A primer on partial least squares structural equation modeling (PLSSEM). Sage publications.

[25] Hair, J. F., Anderson, R. E., Babin, B. J., \& Black, W. C. (2010). Multivariate data analysis: A global perspective (Vol. 7).

[26] Hasan, H. Q., \& Al-Sheikli, A. I. (2020). strategic success in the interactive relationship between local politics and strategic supremacy case study in dhi qar governorate. International Journal of Research in Social Sciences and Humanities, 10(2), 423432. https://doi.org/10.37648/ijrssh.v10i02.042

[27] Hast,Susana(2016). Spheres of Influence in International Relations. Routledge

[28] Henseler, J., Dijkstra, T. K., Sarstedt, M., Ringle, C. M., Diamantopoulos, A., Straub, D. W., ... \& Calantone, R. J. (2014). Common beliefs and reality about
PLS: Comments on Rönkkö and Evermann (2013). Organizational research methods, 17(2), 182-209.

[29] Henseler, J., Ringle, C. M., \& Sinkovics, R. R. (2009). The use of partial least square modeling in international marketing. New Challenges to International Marketing Advances in International Marketing, 20, 277-319.

[30] Hoyer a, Wayne $\square$ \& Kroschke Mirja b \& Schmitt Bernd $c$ \& Kraume Karsten $d \&$ Shankar Venkatesh e(2020). Transforming the Customer Experience Through New Technologies. Journal of Interactive Marketing 51 (2020) 57-71

[31] Jones, B. (2015). "A climacteric of corporate crisis and over-reach". In Corporate Power and Responsible Capitalism?: Towards Social Accountability. . Cheltenham, UK: Edward Elgar Publishing. doi:

https://doi.org/10.4337/9781784717285.00009

[32] Kodama, M. (2018). "Strategic innovation for sustainable growth: reviews of existing capabilities theories, and new propositions". In Sustainable Growth Through Strategic InnovationDriving Congruence in Capabilities. Cheltenham, UK: Edward Elgar Publishing. doi:

https://doi.org/10.4337/9781785366383.00007

[33] Kotze, J. G. (2003). Strategic supremacy in the hypercompetitive 21st century. South African Journal of Economic and Management Sciences, 6(1),

99-

117. https://doi.org/10.4102/sajems.v6i1.3328

[34] Lars Norqvist (2019). Analysis of the Digital Transformation of Society and its Impact on Young People's Lives . the European Union-Council of Europe youth partnership

[35] Laudon Kenneth C.\& Laudon Jane P.,(2016) Essentials of MIS 14th edition, PEARSON, 2016

[36] Lemon, K. N., \& Verhoef, P. C. (2016). Understanding customer experience throughout the customer journey. Journal of Marketing, 80(6), 69-96 
[37] Loebbecke, Claudia,(2003)Digital Goods: An Economic Perspective,Encyclopedia of Information Systems,Elsevier,635-647,ISBN 9780122272400, https://doi.org/10.1016/B0-12227240-4/00043-5.

[38] Margherita, E.G.; Bua, I.(2021) The Role of Human Resource Practices for the Development of Operator 4.0 in Industry 4.0 Organisations: A Literature Review and a Research Agenda. Businesses MDPI Journal 2021, 1, 18-33. https://doi.org/ 10.3390/businesses 1010002

[39] Mohammed Dheyaa Talib \& . Mohammed .Nisreen Jasim(2021). The relationship between Alertness entrepreneurial and strategic supremacy. Turkish Journal of Computer and Mathematics Education,12(13), 2541-2555

[40] Nambisan, S., Lyytinen, K., Majchrzak, A., \& Song, M. (2017). Digital Innovation Management: Reinventing innovation management research in a digital world. MIS quarterly, 41(1).

[41] Neufeind, M., O'Reilly, J. and Ranft, F. (Eds.). (2018). Work in the digital age: Challenges of the fourth industrial revolution. Rowman and Littlefield Ltd.

[42] O'orman, C. (1997). Success Strategies in High-Growth SMEs, in Technology, Innovation, and Enterprise-The European Experience. Ed. D. JonesEvans and $M$. Klofsten. London, England: Macmillan Publishers, 179- 208

[43] OECD (2019), How's Life in the Digital Age?: Opportunities and Risks of the Digital Transformation for People's Well-being, OECD Publishing, Paris. http://bit.ly/HiLDigital@OECD_STAT $\mid$ wellbeing@oecd.org

[44] OECD(2020).A ROADMAP TOWARD A COMMON FRAMEWORK FOR MEASURING THE DIGITAL ECONOMY, Report for the G2O Digital Economy Task Force SAUDI ARABIA, 2020

[45] Palestinian Central Bureau of Statistics, 2018. General Census of Population, Housing and Establishments 2017, Final Results Establishments Report. Ramallah - Palestine
[46] Parry, E., \& Strohmeier, S. (2014). HRM in the digital age-digital changes and challenges of the HR profession. Employee Relations.

[47] Parry, E., \& Strohmeier, S. (2014). HRM in the digital age-digital changes and challenges of the HR profession. Employee Relations.

[48] Rashid, S. A., \& Muttar, L. A. (2020). The role of organizational agility in enhancing strategic supremacy of organizations in dynamic environments: An analytical study in a number of private universities and colleges in the Middle Euphrates region in Iraq. Muthanna Journal of Administrative and Economic Sciences, 10(2), 21-47.

[49] Richter, Nicole F., Gabriel CepedaCarrión, José L. Roldán Salgueiro, and Christian M. Ringle. 2016. European management research using partial least squares structural equation modeling (PLSSEM). European Management Journal 34: 589-97.

[50] Rieple, A., DeFillippi, R., \& Wikström, P. (2016). "Introduction". In International Perspectives on Business Innovation and Disruption in Design. Cheltenham, UK: Edward Elgar Publishing. doi: https://doi.org/10.4337/9781784716646.00005

[51] Ringle, C. M., Sarstedt, M., \& Straub, D. W. (2012). A critical look at the use of PLSSEM in MIS quarterly. MIS Quarterly, 36(1), iii-xiv.

[52] Sarstedt, M., Hair Jr, J. F., Cheah, J. H., Becker, J. M., \& Ringle, C. M. (2019). How to specify, estimate, and validate higher-order constructs in PLS-SEM. Australasian Marketing Journal (AMJ), 27(3), 197-211.

[53] Strauss, K. (2018). Labour geography 1: Towards a geography of precocity? Progress in Human Geography, 42(4), 622-630. https://doi:10.1177/0309132517717786

[54] Strohmeier ,Stefan(2020). Digital human resource management: A conceptual clarification. German Journal of Human Resource Management Zeitschrift für Personalforschung, 34(1),3- 
19.DOI: https://doi.org/10.1177/23970022209 21131

[55] The World Bank Developing Digital Services in the West Bank and Gaza (P1743552020, Project Information Document [56] Thérin, F., Appio, F. P., \& Yoon, H. (Eds.). (2019). "Introduction to the Handbook of Research on Techno-Entrepreneurship, Third Edition". In Handbook of Research on TechnoEntrepreneurship, Third Edition. Cheltenham, UK: Edward Elgar Publishing. doi: https://doi.org/10.4337/9781786439079.00006

[57] Thuethongchai ,Nopsaran , , Taiphapoon Tatri, Chandrachai Achara \& Triukose Sipat (2020). Adopt Big-Data Analytics to Explore and Exploit the New Value for Service Innovation.MDPI journal. . Sci., 9, 29; https:// doi:10.3390/socsci9030029

[58] Valtakoski, Aku \& Rönkkö, Mikko(2010).Diversity of Business Models in Software IndustryConference: Software Business - First International Conference, ICSOB 2010, Jyväskylä, Finland, June 21-23, 2010. Proceedings 1-12

[59] Vial, G. (2019), "Understanding digital transformation: a review and a research agenda", The Journal of Strategic Information Systems, 28(2), 118-144.

[60] Weiling Ke, Chuan-Hoo Tan, Choon-Ling Sia \& Kwok-Kee Wei (2012) Inducing Intrinsic Motivation to Explore the Enterprise System: The Supremacy of Organizational Levers, Journal of Management Information Systems, 29:3, 257-290, DOI: 10.2753/ MISO7421222290308 To link to this article: https://doi.org/10.2753/MIS0742-1222290308

[61] Weinman, Joe. (2015). Digital Disciplines: Attaining Market Leadership via The Cloud, Big Data, Social, Mobile, and The Internet of Things : John Wiley \& Sons Inc
[62] Wengler,
S., Hildmann,
G. and Vossebein, U. (2021),
"Digital transformation in sales as an evolving process", Journal of Business \& Industrial Marketing, $\quad 36 \quad$ (4), 599- 614. https://doi.org/10.1108/JBIM-03-2020- 0124

[63] Wereda Wioletta \& GRZYBOWSKA Monika(2016). CUSTOMER EXPERIENCE DOES IT MATTER?, MODERN MANAGEMENT REVIEW , MMR, vol. XXI, 23 (3/2016), $p p$. 199-207

https://doi: 10.7862/rz.2016.mmr.35

[64] Yaïci, W.; Krishnamurthy, K.;\& Entchev, E.; Longo, M(2021). Recent Advances in Internet of Things (IoT) Infrastructures for Building Energy Systems: A Review . Sensors 2021 MDPI Joural,, 21, 2152. https://doi.org/10.3390/s21062152

[65] Zee, Han van der \& Strikwerda, Hans. (2003). How to Think and Act Strategically in Times of Economic Uncertainty. Copyright Nolan, Norton \& Co, www.nolannorton.com.

\section{Contribution of Individual Authors to}

the Creation of a Scientific Article (Ghostwriting Policy)

Khtib Ohoud, carried out the Conceptualization Ideas; formulation or evolution of overarching research goals and aims. Data curation, simulation and the optimization, Writing - original draft, statistics.

Alshawabkeh Khaled, was responsible for Supervision, Oversight, and leadership responsibility for the research activity planning and execution, including mentorship external to the core team, as well as validation.

\section{Creative Commons Attribution License 4.0 (Attribution 4.0 International, CC BY 4.0)}

This article is published under the terms of the Creative Commons Attribution License 4.0

https://creativecommons.org/licenses/by/4.0/deed.en_US 
Table 5. Reliability Measurement of Constructs

First-order construct

$\mathrm{BM}$

BM1

BM2

BM3

$\mathrm{BM} 4$

BM5

CE

Customer Experience $(\mathrm{CA}=0.843 ; \mathrm{CR}=0.885 ; \mathrm{AVE}=0.564)$

Digital Process $(\mathrm{CA}=0.739 ; \mathrm{CR}=0.852 ; \mathrm{AVE}=0.658)$

Influence on people $(\mathrm{CA}=0.872 ; \mathrm{CR}=0.904 ; \mathrm{AVE}=0.610)$ 
Table 6. Reliability Measurement of Constructs- Second-order construct 


\begin{tabular}{lcr} 
IOP & Influence on people & 0.859 \\
SS & Strategic Supremacy (CA=0.647; CR $=0.819 ;$ & \\
& AVE=0.602) & \\
SOI & Sphere of Influence & 0.809 \\
C. Con & Competitive Configuration & 0.775 \\
C.Com & Competitive Compression & 0.742 \\
\hline
\end{tabular}

Table7. Fornell-Larcker Criterion for first order construct

\begin{tabular}{|l|l|l|l|l|l|l|l|l|}
\hline & BM & C.Com & C.Con & CE & D.HR.M & DP & IOP & SOI \\
\hline BM & $\mathbf{0 . 7 6 7}$ & & & & & & & \\
\hline C.Com & 0.499 & $\mathbf{0 . 7 8 2}$ & & & & & & \\
\hline C.Con & 0.129 & 0.369 & $\mathbf{0 . 7 9 4}$ & & & & & \\
\hline CE & 0.587 & 0.513 & 0.086 & $\mathbf{0 . 7 5 1}$ & & & & \\
\hline D.HR.M & 0.581 & 0.592 & 0.189 & 0.614 & $\mathbf{0 . 7 4 6}$ & & & \\
\hline DP & 0.483 & 0.378 & 0.177 & 0.646 & 0.466 & $\mathbf{0 . 8 1 1}$ & & \\
\hline IOP & 0.507 & 0.504 & 0.217 & 0.644 & 0.569 & 0.587 & $\mathbf{0 . 7 8 1}$ & \\
\hline SOI & 0.232 & 0.431 & 0.410 & 0.358 & 0.397 & 0.234 & 0.479 & $\mathbf{0 . 7 6 2}$ \\
\hline
\end{tabular}

Note: Diagonals in bold represent the square root of each construct AVE. Off-diagonal represent the constraint's correlation.

Table 10. Path Coefficient of Research Direct Hypothesis

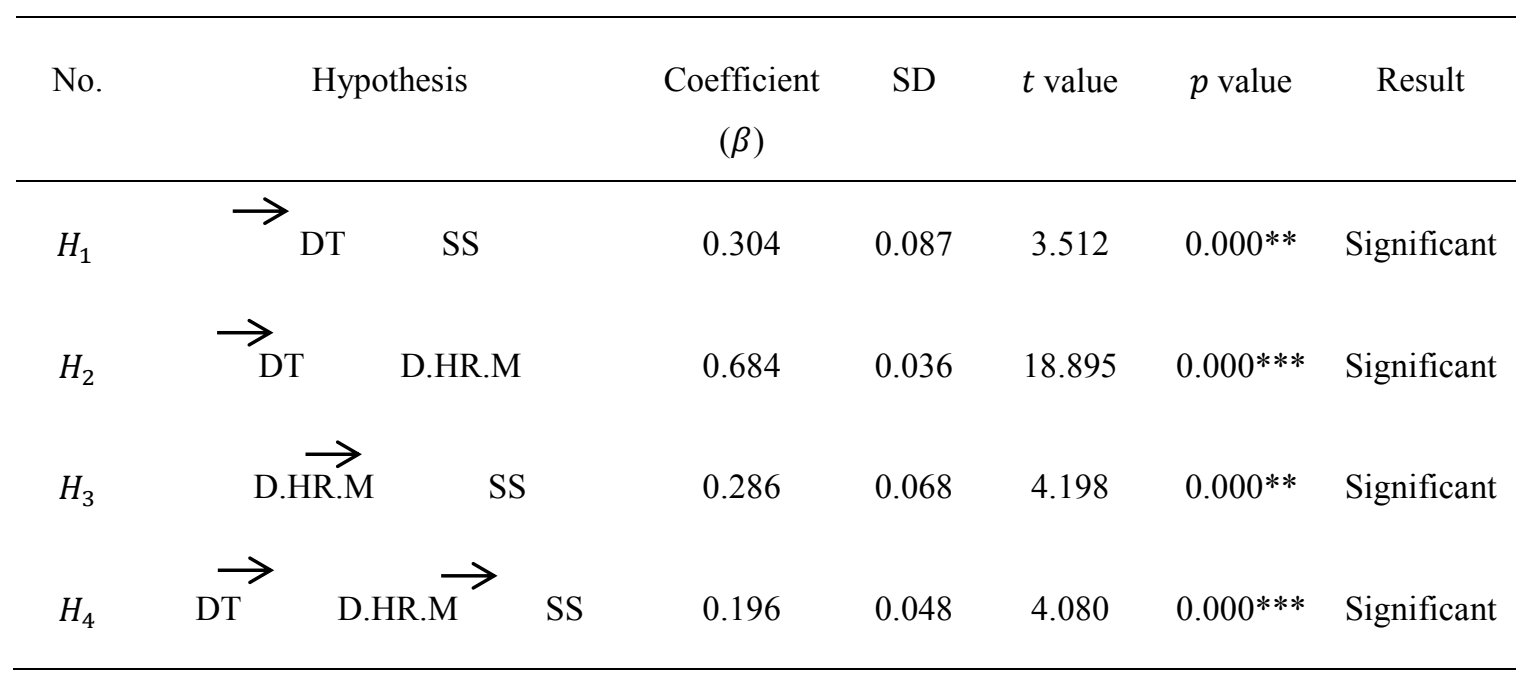

Note: *** a significant relation at $1 \%$.

Table 11. Assessment of Coefficient of Determination and Predictive Relevance

\begin{tabular}{ccccc}
\hline $\begin{array}{l}\text { Endogens } \\
\text { variables }\end{array}$ & $R^{2}$ & SSO & SSE & $Q^{2}=1-S S E / S S O$ \\
\hline D.HR.M & 0.467 & 1608.000 & 1209.788 & 0.248
\end{tabular}




\section{SS}

0.293

2211.000

2000.597

0.095

Note: $\mathrm{SSO}=$ Total Sum of Square; $\mathrm{SSE}=\mathrm{Sum}$ of Square due to error

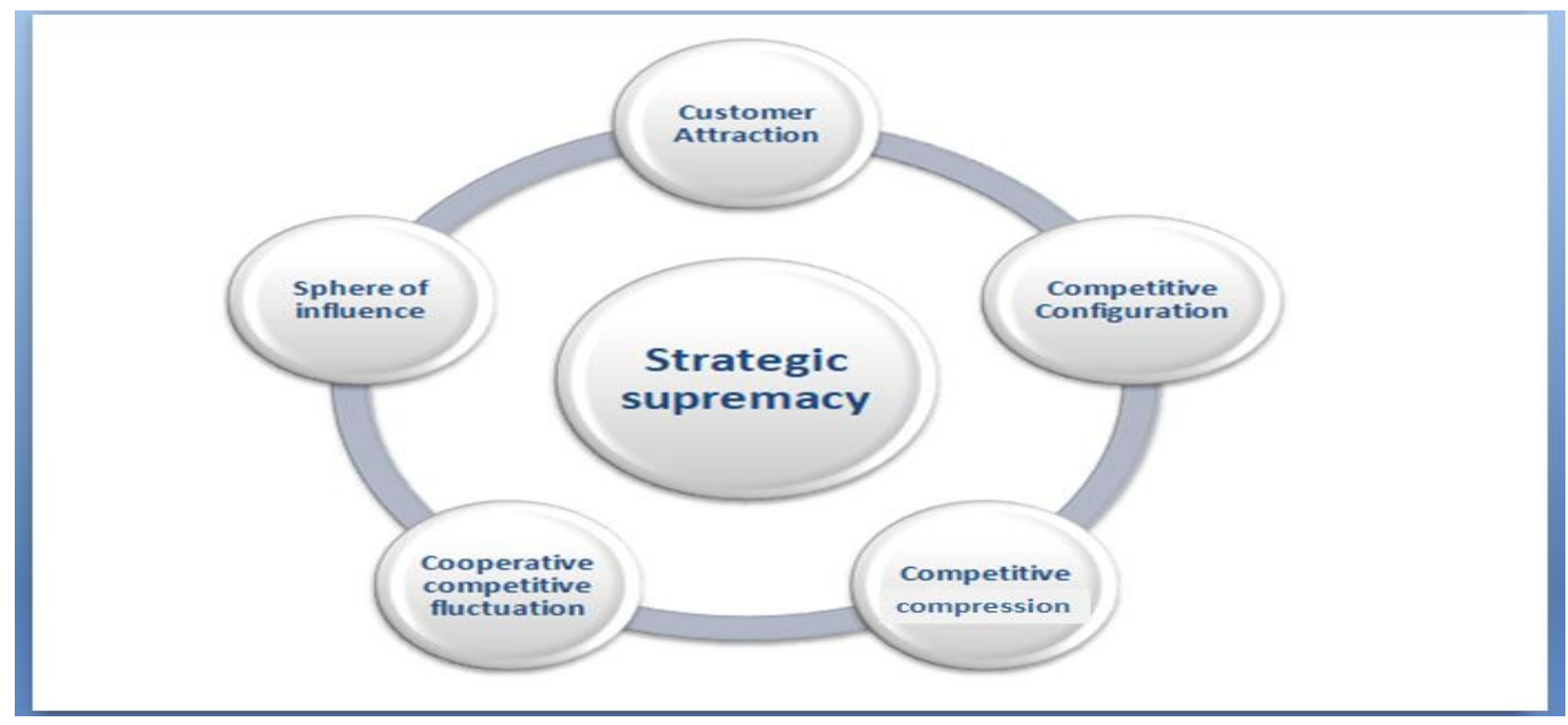

Figure 1. Dimensions of Strategic Supremacy from a Marketing Perspective. Figure prepared by researchers. 


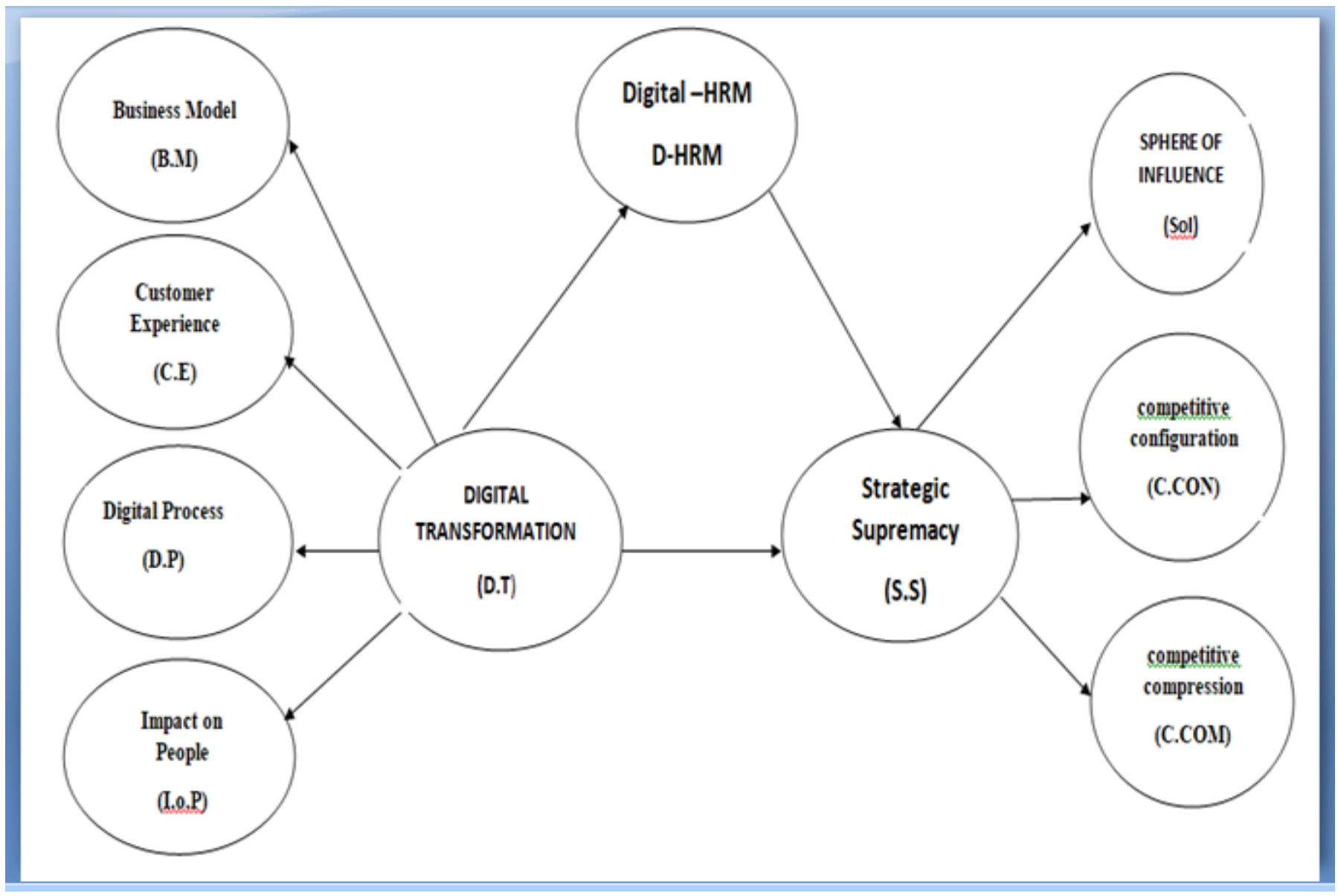

Figure2: Study Model 


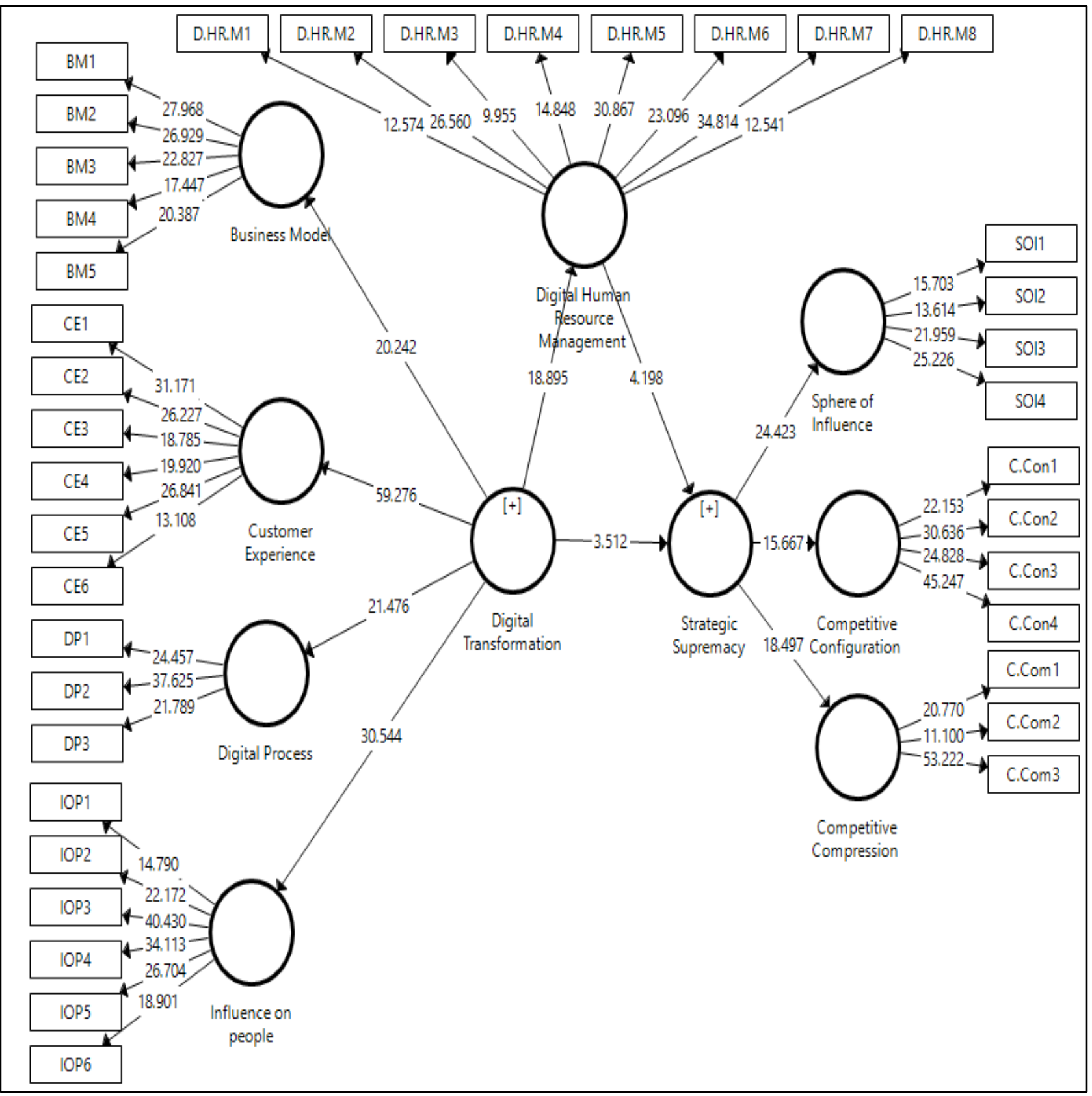

Figure 3: Structural Model 